\title{
Girişimcilik Faaliyetlerinde Teknoparkların Önemi: Afyon-Uşak Zafer Teknoloji Geliştirme Bölgesi Örneği ${ }^{*}$
}

\author{
Importance of Technopark in Entrepreneurship Activities: Afyon-Usak Zafer \\ Technology Development Zone Example
}

\author{
Prof. Dr. Tuğrul KANDEMIR (D) 1 , Dr. Öğr. Üyesi Berfu İLTER (D)2
}

\begin{abstract}
$\ddot{O} z$
Ekonomik kalkınma ve sürdürülebilir gelişmeye katkı yapma, yeni kavramlar, yeni ufuklar yaratma yönünden anlamlı fikirleri hayata geçirme merkezleri olan teknoparklar, tüm bunları sanayi kuruluşlarını ve üniversiteleri bir araya getirerek sağlamaktadırlar. Teknoparklar, piyasanın yetersiz olduğu AR-GE ve yenilikçi faaliyetler için altyapı sağlayarak, vergi ya da genişletilmiş teşvik araçları ile girişimcileri projelerini hayata geçirme hususunda teşvik etmektedirler. Girişimcilerin, başarılı bir iş kurabilmeleri ve yönetebilmeleri için gerekli olan bilgiye ulaşabilmelerinde desteğe gereksinim duymaktadırlar. $\mathrm{Bu}$ gereksinim; üniversitelerin kütüphane, laboratuvar, bilgisayar gibi fiziki imkânlarının kullanımının yanı sıra uzman kadro, öğrenciler, ortak projeler geliştirme ve danışmanlık hizmetleri ile de karşılanabilmektedir. Teknoparkların sunmuş olduğu bu imkânlar sayesinde; girişimciler toplumun güncel ve gelecekteki ihtiyaçlarına çözümler üreterek daha yaşanabilir bir dünya için risk alabileceklerdir. Teknoparklar, mucit girişimcilerin bilim teknoloji, AR-GE faaliyetlerini geliştirme ve teknoloji transferlerine imkân tanımaktadırlar. Çalışmada, özellikle yeni fikir ve buluşları uygulamaya yönelik girişimcilik faaliyetlerinde teknoparkların katkı ve önemini vurgulamak amaçlanmaktadır. Çalışmada nitel araştırma yöntemi uygulanmıştır. Çalışmanın evrenini, Afyon-Uşak Zafer Teknoloji Geliştirme Bölgesi'ndeki girişimci işletmeler oluşturmaktadır. Sonuç olarak, küreselleşen dünyamızda katma değeri yüksek teknolojileri üreten girişimciliğin desteklenmesi, mikro anlamda işletmelerin ülke ekonomisine katkılarını artırmakta; makro anlamda ise ülkeleri ekonomik anlamda oldukça ilerilere taşıyabilecek bir unsur olarak görülmektedir. Bu bağlamda teknoparkların kurulması ve varlıklarını sürdürmelerinin; gerek girişimcilerin, gerekse ülkelerin kalkınmasında önemli unsurlar olduğu göz önünde bulundurulmalıdır.
\end{abstract}

Anahtar Kelimeler: Girişimcilik, teknopark, Afyon-Uşak Zafer Teknoloji Geliştirme Bölgesi

Makale Türü: Araştırma

\begin{abstract}
By bringing technoparks universities and industrial establishments together; university-indusry collaboration, to contribute to economic development and sustainable development, to introduce new concepts, to create new horizons, and to make meaningful ideas. Technoparks encourage entrepreneurs with tax or extended incentive tools and projects by providing infrastructures for AR-GE and innovative activities where the market is insufficient. Entrepreneurs need support to get the information they need to build and manage a successful business. These needs are covered not only use of physical facilities such as libraries, laboratories and computers of universities, but also it can be met with expert staff, students, joint projects development and consultancy services. Thanks to these possibilities offered by technoparks; entrepreneurs will be able to take risks for a more liveable world by developing solutions to the current and future needs of the community.
\end{abstract}

\footnotetext{
* Bu çalışma, 23-25 Mart 2018 tarihinde gerçekleştirilen “International Congress on Science and Education UBEK-ICSE 2018”de sunulan bildirinin genişletilmiş halidir. / Afyon-Uşak Zafer Teknopark ile ilgili verilere: http://www.zaferteknopark.com.tr/ adresinden ulaşılmıştır. Erişim 31.05.2018 tarihine kadar sağlanmıştır.

${ }^{1}$ Afyon Kocatepe Üniversitesi/ İ.I.B.F, tkandemir@aku.edu.tr.

${ }^{2}$ Afyon Kocatepe Üniversitesi/ İ.İ.B.F, berfu@ aku.edu.tr.
}

Atıf için (to cite): Kandemir, T ve İlter, B. (2019) Girişimcilik Faaliyetlerinde Teknoparkların Önemi: Afyon-Uşak Zafer Teknoloji Geliştirme Bölgesi Örneği. Afyon Kocatepe Üniversitesi Sosyal Bilimler Dergisi, 21(4), 1216-1229. 
It was aimed to emphasize the contribution and importance of technoparks in the study, especially in entrepreneurship activities to pass on new ideas and discoveries. Qualitative research method was applied in order to get results. The sample of study constitutes entrepreneurial businesses located in Afyon-Usak Zafer Technology Development Zone. As a result, in our globalizing world, supporting entrepreneurship that produces high value added technologies increases the contribution of micro-enterprises to the economy; in macro sense, it is seen as an element that can carry countries in economic terms. In this context, the establishment of technoparks and their existence; it should be taken into consideration that they are important elements in the development of both entrepreneurs and countries.

Keywords: Entrepreneurship, technopark, Afyon-Usak Victory Technology Development Zone

Paper Type: Research

\section{Giriş}

Dünyada yaşanan teknolojik gelişmeler, ekonomik, sosyal ve politik değişimlere neden olmuştur. Bu değişimler ise teknolojik yaratıcılık, araştırma ve geliştirme, girişimcilik ve küçük işletmeler, kalkınma ve gelişmenin önemli bir aracı olarak ön plana çıkmaktadır. Teknoparkteknokent kavramının ortaya çıkmasında ise; girişimciler tarafindan yürütülen araştırmageliştirme faaliyetlerinin sonuçlarının ticari hayata geçirilmesi çabaları etkili olmuştur (Harmancı ve Önen, 1999:1).

İlk olarak teknopark fikri1950 yılında yürüttükleri araştırmaları ticarileştirmek isteyen bir grup araştırmacının gayretleri sonucu ve Stanford Üniversitesinin öncülüğünde Amerika'da ortaya çıkmıştır. Dünyada en çok tanınan bu teknopark günümüzde "Silikon Vadisi" olarak bilinmektedir. Google, Intel, Yahoo gibi birçok küresel firma bu teknopark içinde yer almaktadır. Teknoparklar bugün Silicon vadisinin önderliğinde, dünyanın her yerinde inovatif düşüncenin uygulamaya geçirildiği önemli merkezler olmuşlardır (Başalp ve Yazlık, 2006: 275). Türkiye'de İpek tarafından yapılan çalışmada, "üniversite sanayi ve araştırma merkezleri, TÜBİTAK, KOSGEB vd. kuruluşlardan destek alınarak işbirliği içinde yapılan çalışmaların, girişimcilerde inovasyon hakkında daha fazla bilinçlenme ve inovasyona daha fazla yönelme gibi olumlu etkilerin oluştuğu" görüşü desteklenmektedir (İpek, 2015: 123).

İnovatif düşünce ülkelerin rekabet avantajının en önemli göstergesi olmuştur. Ülkelerin inovasyonu teşvik ederek, uluslararası alanda performanslarını artırabilmeleri için en önemli uygulamalardan birisi; "üniversite sanayi iş birliğini geliştirmek" tir. Bu amaçla "Teknopark Modeli" uygulamaya alınmıştır. Türkiye'de teknoparklar; biyoteknoloji, uzay araştırmaları ve uydu teknolojisi, elektronik, yenilenebilir enerji kaynakları, gıda teknolojisi, hayvan ve bitki geliştirme alanlarında çalışmalar amaçlanarak 1980'li yıllarda kurulmaya başlanmıştır (Tepe ve Zaim, 2016: 22)

Bu bağlamda Türkiye'de de 6Temmuz 2001 tarihinde Resmi Gazete' de yayımlanarak yürürlüğe giren "Teknoloji Geliştirme Bölgeleri Kanunu" hazırlanmıştır. Bu kanunla; üniversite sanayi işbirliğini etkinleştirmek, üniversitelerde sanayinin gereksinimleri ile örtüşen bilimsel ve teknolojik çalışmaların gerçekleştirilmesi ve ülke sanayisinin inovasyon yeteneğini artırmak amaçlanmıştır. Kanun, 12 Mart 2011 tarihinde yapılan değişikliklerle güncellenmiştir (Gülbaş, 2011: 139). Kanunun uygulanmasına ilişkin usul ve esasları düzenlemek için 12 Mart 2014'de yönetmelik yayınlanmıştır. Teknoloji Geliştirme Bölgesi çalışması Türkiye'de ilk olarak Orta Doğu Teknik Üniversitesi (ODTÜ) tarafından 1991 yılında başlatılmıştır. Teknopark çalışmaları Türkiye'de Sanayi ve Ticaret Bakanlığı'nın kontrolü ve yetkisi ile sürdürülmektedir (Başalp ve Yazlık, 2006: 275). Afyon-Uşak Zafer Teknoloji Geliştirme Bölgesi de bu kanun ve yönetmelik kapsamında faaliyetlerini sürdürmektedir.

Günümüz koşullarında girişimcilik faaliyetlerinin başarılı olabilmesi için, teknoparkların katkısı ve önemine vurgu yapılmaktadır. Çalışmada sırasıyla; girişimcilik faaliyetleri, 
teknoparkların tanımı, gelişimi ve son olarak da Afyon-Uşak Zafer Teknoloji Geliştirme Bölgesi ile ilgili bilgiler yer almaktadır. Nitel araştırma yöntemine göre, Zafer Teknoparkta yer alan girişimcilerin beklenti ve memnuniyetleri değerlendirilmektedir.

\section{Girişimcilik Faaliyetleri}

Girişimci, yeni bir fikir ya da bir girişim planına sahip ve bu planı gerçeğe dönüştürdüğünde oluşabilecek risklerin ve giderlerin farkında olan kişidir. Girişimcinin işi fikir üretmekle sonlanmaz. Fikri işe dönüştürebilmek, belirli bir sermaye desteği ile mümkündür ve o işi sürdürebilmek girişimcinin yüzleşmesi gereken zorluklardan en önemlisidir. Dolayısıyla girişimci fikrini ticarileştirmek zorundadır (Ergen, 2014:36).

Bilişim alanındaki gelişmeler doğrultusunda, girişimciliğin gerçekleşme şartlarında da önemli değişimler ve olumlu yenilikler söz konusu olmuştur. Önceleri girişimcilik için üç temel unsur; toprak, sermaye ve emeğin varlığı, girişimcinin cesaret ve becerisinden bağımsız üç temel unsur olarak görülmekteydi. Başka bir ifadeyle, önceleri risk alan, cesur ya da firsatları yakalamayı bilen girişimciler, tüm bu olumlu özelliklerine rağmen toprak, sermaye ya da hükmedebilecekleri emek unsurlarına sahip değillerse, sadece girişimcilik becerileri dikkate değer iş büyüklükleri yaratamıyordu. Ancak, bilgi çağının getirdiği gelişmelerle bugünün girişimcileri için şartlar çok daha olumlu görülmektedir. Zaman içerisinde küçük ya da büyük iş girişimleri için yukarıda sayılan üç unsur da geçmişe oranla önemini kaybederek, yerini; "iş fikri" ve "girişimcilik" unsurlarına bırakmıştır (Halıcı, 2008:2).

Girişimcilerin bilgi toplumuna dönüşümle birlikte iş yapma biçimleri değişmiş, ekonomik ve beşeri sermayelerinin yanında sosyal ve kültürel sermayelerinin de önemi ortaya çıkmıştır. Girişimcinin başarısını büyük ölçüde belirleyen girişimcinin sermayesi dört alt sermayeden oluşmaktadır. Bu konudaki kavramsallaştırmaya ilişsin şekil aşağıda yer almaktadır (Cansız, 2017:61).

Şekil 1.Teknoloji tabanlı girişimcilerin sahip oldukları sermaye
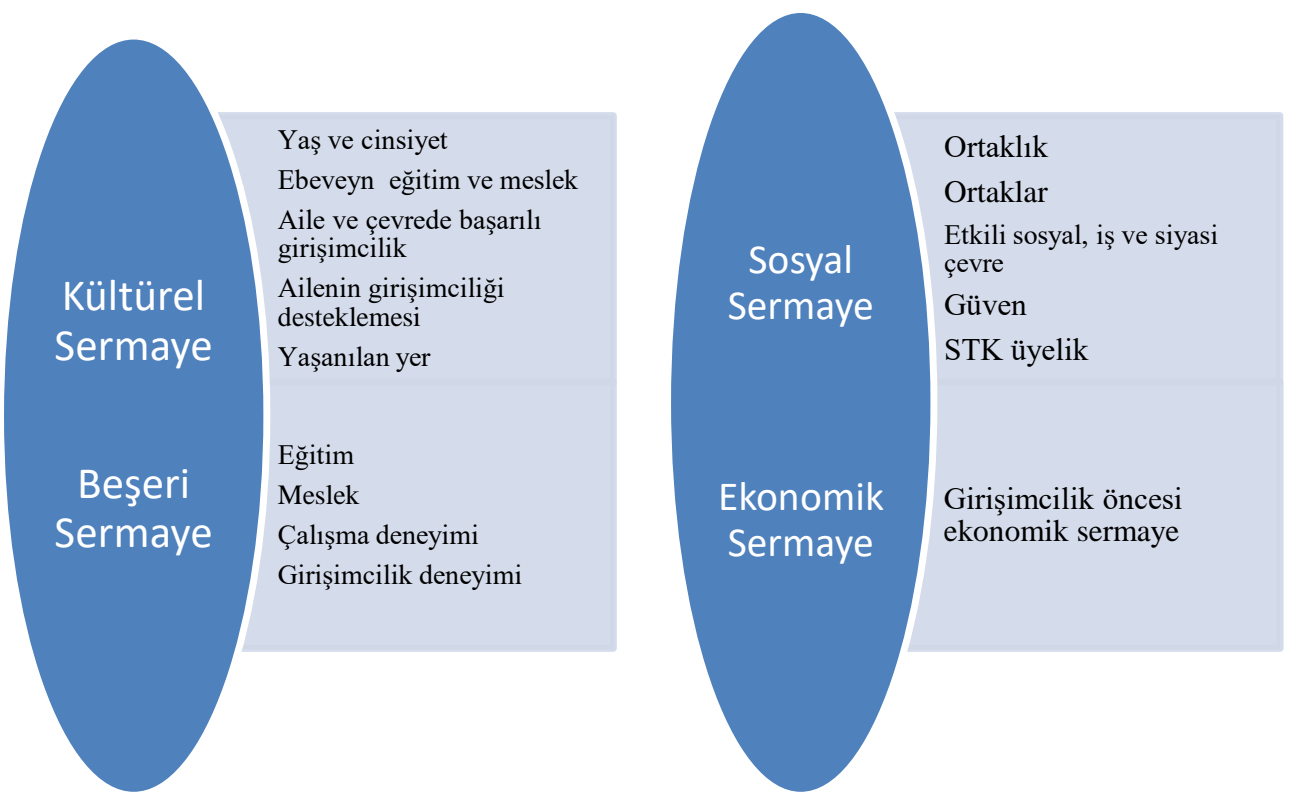

Kaynak: Cansı, 2017:64

\section{Teknopark Tanımı}

Teknoloji, üretim yöntem ve makinalarında, ürünlerde, “yenilik”(inovasyon) yaratmay1; bu yenilikler sayesinde üretimi artırmayı, verimliliği yükseltmeyi, rekabet üstünlügünü ve kârı 
artırmayı sağlayan bir unsur olarak tanımlanmaktadır (Marangoz,2016a:311). Büyük işletmeler, üniversiteler, start-up işletmelerinin tümünü bir arada tutan bir ekosistem; teşvik edici yasal düzenlemeler, tedarikçiler, insan kaynağı altyapısı ve finansmandan oluşan bu oluşum modeli, dünyada birçok teknolojik yeniliğe ve yıldızı yükselen şirketlere ev sahipliği yapmıştır. Türkiye'de bu model yasal bir düzenleme ile tanımlanarak “Teknoloji Geliştirme Bölgesi” ya da “Teknopark" olarak adlandırılmıştır (Yalçıntaş, 2014:86).

Teknoparklarla ilgili dünyada ve ülkemizde görülen uygulamalardan yola çıkarak teknoparkları, "sanayi üniversite işbirliğinin gerçekleştiği, güçlü ve büyük bir üniversite yakınında kurulan, üniversitelerin birikmiş bilgi, araştırma, ve eğitim potansiyelini, sanayinin mevcut kaynaklarla; bunlarla ilgili ihtiyaç ve sorunları planlı olarak ortak noktada bir araya getiren, sonuçta ortaya çıkan teknolojik ve sinerjik bir buluşu ticarileştiren, bu sayede bölgesel kalkınmaya hizmet eden, devletin varoluş gereği doğal olarak katıldığı; diğer kişi, kurum ve kuruluşların da ekonomik ve sosyal amaçları doğrultusunda katılarak katkı sağladıkları bir yapı" olarak tanımlamak mümkündür(Alkibay vd, 2012: 67).

Teknoparkların temel amaçları; teknoloji yoğun sanayi alanlarını bulundukları yerlerde güçlendirerek, yeni sanayi bölgelerinin gelişimini desteklemektir (Harmancı ve Önen, 1999:1)

Günümüzde oldukça az sayıda sanayi kuruluşu yeni ürün geliştirebilecek ya da ürettiği ürünü teknolojik olarak daha üstün hale getirebilecek alt yapıya sahiptir. İnovasyonu sağlayan yapının en önemli bileşenleri; bilimin üretildiği üniversiteler, üretilen bilginin ürüne (teknoloji) dönüştürülerek pazarlandığı şirketler ve bu sistemin rahat işleyeceği ortamı hazırlayan yönetim (devlet) mekanizmasıdır. Bu üç bileşen ne kadar uyumlu ve verimli çalışırsa, ekonomik sisteme katkıları da o kadar artacaktır. Bu bileşenleri yani üniversiteleri ve girişimcileri bir araya getirecek ara yüzler; teknoparklar, Ar-Ge merkezleri, teknoloji transfer ofisleri, kuluçkalar vb. yapılardır (Yalçıntaş, 2014:87).

\subsection{Teknoparklarla İlgili Önemli Kavramlar}

Girişimciliğin tohumlarının atıldığı ve geliştiği merkezlerde; girişimciliğin ortada yer aldığı ve etrafında farklı özellikte kurumlarla etkileşimini sağlayan bir çevre gelişmiştir. Bu çevre, belirli bir düzen ve denge ile girişimci ve diğer paydaşların etkileşimini düzenler. Girişimcilik ekosistemi, bireyler, kurum ve kuruluşların oluşturduğu, bulunduğu bölgenin ihtiyaçlarına göre kendi kendini geliştiren, çoğunlukla devlet kaynakları ile desteklenen, girişimcileri yönlendiren ve onların üretimine katkıda bulunan bir sistemdir (Özkaşıkçı, 2013:110).

Türkiye'de mevcut en iyi işleyen ve tam kapasite girişimcilere destek veren en iyi yapılanma teknoparklardır. Teknoloji ihraç etmeyi amaç edinen her ülke, bu alt yapıyı oluşturmak ve desteklemek durumundadır. Bu durum bir ön koşul değildir, ancak teknolojik gelişmeleri barındıracak en uygun düzen bu yapılar altında kurulmaktadır. Girişimcilere yapısal anlamda en düzenli desteği, kuluçka merkezleri sunar. Türkiye'de genelde teknoparkların içinde yer alan kuluçka merkezleri; girişimcilere çalışacak alan, gerekli ofis malzemeleri, fikir aşamasındaki kuruluşlarda fikrin geliştirilmesi desteği, ar-ge çalışanları için ürün geliştirme ve örnekleme imkânı, pazar araştırma imkânı, şirket kurma ve finansman arama konularında destek sağlamaktadırlar. Ayrıca bu merkezlerde yaşananlar ve yaratılan çözümler diğer girişimciler tarafından gözlenerek, farklı proje sahiplerinin birbirlerine destek olmalarını mümkün kılmakta ve bu sayede girişimciliğin özündeki paylaşımcılık ruhunu da ortaya çıkarabilmektedir (Özkaşıkçı, 2013:146-155).

Ayrıca, araştırma laboratuvarları, sanayi kuruluşları ve üniversitelerin; teknoparklar ile aynı ortamda bulunmaları, bilim teknoloji ve AR-GE faaliyetlerini geliştirerek teknoloji transferine imkân tanıyan yapıları ile mucit girişimciler için önemli firsatlar sunmaktadırlar (Bülbül ve Özbay, 2011:47). Mucitler, karşılaştıkları sorunlara çözüm üretmeye odaklanırlar. Bu odaklanma sayesinde ürün ya da hizmetlerle ilgili özgün ve yaratıc fikirler üretirler. Girişimciler ise daha önceden yaratılmış bir ürün ya da hizmetin nasıl başarılı bir işletmeye dönüşeceği ile 
ilgilidirler. Ancak her iki özelliğin de aynı kişide bir araya gelmesi de mümkündür (Ergen,2014:44). Dolayısıyla teknoparkların mucitlere girişimcilik özelliğini de kazandırdığı ifade edilebilir.

\subsection{Teknoparklar ve Türkiye'de Gelişimi}

Türkiye'de teknoparkların kurulması 1990'lı yıllarda başlamış ve 2001 yılına gelindiğinde mevzuatı oluşturularak kanunla belirli bir zemine kavuşturulmuştur. Bu Kanun dahilinde; toplam 77 adet Teknoloji Geliştirme Bölgesi (Ankara 8, İstanbul 11, Kocaeli 5, İzmir 4, Gaziantep 2, Konya 2, Mersin 2, Antalya 2 ve Kayseri, Trabzon, Erzurum, Isparta, Muğla, Eskişehir, Bursa, Denizli, Edirne, Elazı $\breve{g}$, Sivas, Diyarbakır, Tokat, Sakarya, Bolu, Kütahya, Samsun, Malatya, Urfa, Düzce, Çanakkale, Kahramanmaraş, Tekirdağ, Van, Adana, Çorum, Manisa, Niğde, Burdur, Yozgat, Karabük, Kırıkkale, Balıkesir, Hatay, Karaman, Afyonkarahisar, Aydın, Batman, Osmaniye, Zonguldak ve Nevşehir'de 1'er adet) kurulmuştur (btgm.sanayi.gov.tr, 2018).

Teknoparkların kurulması, faaliyete geçmesi ve önemli etkiler sağladığı dönem ise 20032017 yılları arasında olmuştur. Türkiye'de son 15 yılda yenilik, Ar-Ge ve girişimcilik alanlarında oldukça önemli gelişmeler sağlanmış ve sağlanmaya devam etmektedir. Teknoparklar (Teknoloji Geliştirme Bölgeleri) girişimcilik ekosistemin araçlarından birisi olarak aynı dönemde benzer gelişmeler göstermiştir. Teknoparklarda 2001-2016 yılları arasında toplam 2,3 milyar dolarlık ihracat gerçekleşirken 2016 yılında ihracat 200 milyon doları bulmuştur (Cansız, 2017:8-52). Nisan 2018 verilerine göre; Bilecik ve Ușak illerinde ek alan olarak kurulan Teknoparklar da dâhil olmak üzere ülkemizde 51 ilde Teknopark bulunmaktadır. Ayrıca 77 Teknoloji Geliştirme Bölgesi'nden 56's1 faaliyetine devam etmektedir. Toplam girişimci firma sayıs1 4.916, toplam personel say1s1 $47.525^{\prime}$ 'dir. Teknoparklarda devam eden proje sayıs1 8.316, tamamlanan proje sayıs1 27.749, toplam satış 57.8 milyar TL, toplam ihracat 3.4 milyar USD olarak gerçekleşmiştir (btgm.sanayi.gov.tr, 2018).

\section{Afyon-Uşak Zafer Teknoloji Geliştirme Bölgesi}

4691 Sayılı Teknoloji Geliştirme Bölgeleri Kanunu uyarınca gerekli işlemlerin tamamlanarak, 19.12.2015 tarih ve 29567 Sayılı Resmi Gazetede ilanı ile Afyon Uşak Zafer Teknoloji Geliştirme Bölgesi kurulmuştur. Bölgede toplam 4 alan bulunmaktadır. Bunlar; Afyonkarahisar'da Afyon Merkez Teknopark $153.101 \mathrm{~m}^{2}$, Afyon Kampüs Teknopark $4.623 \mathrm{~m}^{2}$, Uşak'ta ise Uşak Teknopark $20.510 \mathrm{~m}^{2}$ ve Uşak Organize Sanayi Teknopark $6.000 \mathrm{~m}^{2}$ büyüklüğündedir. Kuruluşu takiben Afyon Kampüs Teknopark alanında yer alan $2224 \mathrm{~m}^{2}$ alanda faaliyetlerine başlamak üzere gerekli işlemler tamamlanmıştır.

Bölgenin Resmi Gazete'de yayımlanmasının ardından, Afyon Uşak Zafer Teknoloji Geliştirme Bölgesi Yönetici A.Ş. (ZAFER TEKNOPARK A.Ş.) Afyonkarahisar Ticaret Sicil memurluğunun 23.03.2016 tarih ve 13540 sicil numarası ile tescil ve ilan edilerek tüzel kişiliği onaylanmıştır. Bölge; Türkiye'de farklı iki ilde bulunan yükseköğretim kurumları ortaklığında kurulmuş olan ilk teknopark özelliği ile aktif teknoparklar arasında yer almaktadır.

Zafer Teknopark A.Ş., onyedi ortaklı bir şirkettir, ancak büyük ortaklar Afyon Kocatepe Üniversitesi ve Uşak Üniversitesi'dir. İlk yönetim kurulu toplantısı 01.04.2016 tarihinde yapılmış ve hemen sonrasında proje kabulüne ve 20.07.2016 tarihinden itibaren de girişimci firmalarla kira sözleşmeleri imzalanmaya başlanılmıştır. Afyon Uşak Zafer Teknoloji Geliştirme Bölgesi'nin bölge ilanından sonra imar tadilat işlemleri devam etmekte olup bu işlemlerin tamamlanmasının ardından bina yapımlarına başlanılarak alanların tamamında aktif olarak faaliyete geçilmesi planlanmıştır. Şu anda Zafer Teknopark Afyon Kocatepe Üniversitesi içerisinde yer alan $4613 \mathrm{~m}^{2}$ açık kapalı alanda yer alan $2224 \mathrm{~m}^{2}$ kapalı alanına sahip Kampüs Teknopark'ta 15 ve 23 'er $\mathrm{m}^{2}$ ofislerinde faaliyet göstermektedir. Zafer Teknopark Aralık/2017 itibariyle 15 girişimci firma ile \%100 doluluk kapasitesinde faaliyetlerini sürdürmektedir. Kuruluşundan itibaren Zafer 
Teknopark'ta toplam 32 Ar-Ge projesi bağımsız hakemler tarafindan değerlendirmeye tabi tutulmuştur.

Tablo 1. Teknopark bünyesinde başarı ile bitirilen Ar-Ge projeleri

\begin{tabular}{ll}
\hline Teknopark Ar-Ge proje konusu & Proje Süresi \\
Görüntü Stabilizasyon Sistemi & $6 \mathrm{Ay}$ \\
$\begin{array}{l}\text { Anlamsal Ağ Teknolojisini Kullanarak Tarladan Çatala Gıda } \\
\text { İlenebilirliğin ve Güvenliğinin Sağlanmasının Araşırılması ve }\end{array}$ & $12 \mathrm{Ay}$ \\
İzlenebilirlik Ontolojisinin Geliştirilmesi & \\
SCADA Sistemleri & $18 \mathrm{Ay}$ \\
Uzaktan Canlı Yayın Eğitimi Yazılımı & $18 \mathrm{Ay}$ \\
Master Net Görüntü Yönetim Yazılımı & $12 \mathrm{Ay}$ \\
\hline
\end{tabular}

Tablo 2.Teknopark bünyesinde devam eden Ar-Ge projeleri

\begin{tabular}{|c|c|}
\hline Teknopark Ar-Ge proje konusu & Proje Süresi \\
\hline Asansörlerin Uzaktan İzlenmesi ve Arızalarda Acil Haber Alma Sistemi & 18 Ay \\
\hline Mermer Güçlendirme Sürecinde Robotik Uygulama Geliştirme & 36 Ay \\
\hline Çift Eksenli Güneş Takip Sistemi & 15 Ay \\
\hline Özel Tasarım Mozaik Figürlerinin Robotik Dizimi & 12 Ay \\
\hline $\begin{array}{l}\text { Süt İneklerinde Beslenme ve Sağlık Takibi İçin Rfid Tabanlı Bir } \\
\text { Otomasyon Sisteminin Geliştirilmesi }\end{array}$ & 36 Ay \\
\hline Bilgisayar Destekli Karar Destek ve Denetim Sistemi & 36 Ay \\
\hline $\begin{array}{l}\text { İçme Suyu Depo Kontrol ve İzleme Sisteminin Geliştirilmesi Ve } \\
\text { Uygulanması }\end{array}$ & 18 Ay \\
\hline Mineral Kökenli Atıklardan Hafif Beton Blok Üretimi & 18 Ay \\
\hline $\begin{array}{l}\text { Moleküler Etkileşim İçin Plazmonik Cihaz Otomasyonu } \\
\text { Mermer Üretim Yönetim Sistemi Geliştirilmesi (Mars) }\end{array}$ & $\begin{array}{l}18 \text { Аy } \\
24 \text { Ay }\end{array}$ \\
\hline Mermer Güçlendirme Sürecinde Robotik Uygulama Geliștirme & 24 Ay \\
\hline
\end{tabular}

Tablo 3. Projesini Teknopark bünyesinde tamamlayıp yeni proje sunan firmalara ait proje bilgileri

\begin{tabular}{ll}
\hline Teknopark Ar-Ge proje konusu & Proje Süresi \\
Nesne Tanımlama Ve Sayma Sistemi-(Sektör İ́simleri) & $24 \mathrm{Ay}$ \\
Web Tabanlı Anlamsal Ağ Editörünün Geliştirilmesi & $12 \mathrm{Ay}$ \\
Görüntü İșleme Ve Video Analiz Sistemi & $36 \mathrm{Ay}$ \\
\hline
\end{tabular}

\subsection{Teknoparkın Girişimcilere Sağladığı Mali Destekler ve Sunduğu Avantajlar}

Afyon Uşak Zafer Teknoloji Geliştirme Bölgesi, girişimci firmalara her iki üniversiteden alanında uzman akademisyenler ile iş birliği imkânı sunarak, sanayici ve akademisyen arasında köprü görevini üstlenmektedir. 
Zafer Teknopark, Afyon Kocatepe Üniversitesi ve Uşak Üniversitesi ile sanayi kuruluşları arasında etkin bir iş birliği oluşturarak, üniversitelerin sahip oldukları akademik bilgi ile sektörlerin ticari tecrübelerini Ar-Ge ve inovasyon temelli ortak projelerinde birleştirerek, bölgenin ve ülkenin ekonomik gelişimine katk1 sağlayan bir merkez haline gelmeyi misyon edinmiştir. Bu bağlamda da Tübitak, KOSGEB, Tarım ve Kırsal Kalkınma Yatırımları Projeleri, Kalkınma Ajansları, AB Çerçeve Programları başta olmak üzere diğer tüm ulusal ve uluslararası fonlara ve hibe kaynaklarına erişim konusunda proje hazırlama ve yürütme danışmanlık hizmetleri de vermektedir.

Bölge ayrıca, şirketlerin rekabet avantajı sağlamasında en önemli konular arasında yer alan marka-patent, insan kaynakları ve üretim yönetimi gibi alanlarda da işletmelere profesyonel danışmanlık ve mentörlük hizmetleri sunmaktadır. Girişimci firmalara 4691 sayılı kanun çerçevesinde yer alan gelir ve kurumlar vergisi, işveren katkı payı ve muafiyetlerinden yararlanma avantajları sağlanmaktadır. Ayrıca Zafer Teknopark A.Ş.'de Öğretim elemanlarına araştırma sonuçlarını ticarileştirebilme, şirket kurabilme ve başka bir şirkete ortak olabilme imkânı da sunarak; akademik camianın ticari hayata katılımını artırıcı bir rol üstlenmektedir.

Girişimcilere Sağlanan Avantajlar

- Katma Değer Vergisi Muafiyeti

- Personel Ücret Vergileri Stopaj Teşviki

- Sigorta Primi Teşviki

- Gelir Ve Kurumlar Vergisi Stopaj Teşviki

Öğretim Elemanlarına Sağlanan Avantajlar

Öğretim elemanı;

- Araştırma sonuçlarını ticarileştirebilir

- Şirket kurabilir

- Şirkette yönetici olabilir

- Kurulmuş bir şirkete ortak olabilir ya da yönetiminde görev alabilir

- Döner sermaye kapsamı dışında gelir elde edebilir.

Tablo 4. Zafer Teknopark'a ait diğer istatistikler

\begin{tabular}{|c|c|}
\hline Gösterge Verileri & Mevcut Durum \\
\hline TGB(Teknoloji Geliştirme Bölgesi)'nin Toplam Kapalı Alanı (m2) & $\begin{array}{l}\text { 2,224 (Afyon Kampüs } \\
\text { Teknopark) }\end{array}$ \\
\hline TGB(bölgesi)'nin Toplam Açık Alanı (m2) & $\begin{array}{l}\text { 184,224 (153101 M2 } \\
\text { Afyon+4613 Kampüs } \\
\text { Teknopark+26510 } \\
\text { Uşak Toplam Alan) }\end{array}$ \\
\hline TGB(Teknoloji Geliştirme Bölgesi) nin Kiralanan Toplam Ofis Alanı (m2) & 307 \\
\hline TGB(Teknoloji Geliştirme Bölgesi) nin Kiralanabilen Toplam Ofis Adedi & 15 \\
\hline TGB(Teknoloji Geliştirme Bölgesi) nin Toplam İdari Ofis Adedi & 4 \\
\hline TGB(Teknoloji Geliştirme Bölgesi Yönetici Şirket İdari Personel Sayısı & 5 \\
\hline TGB(Teknoloji Geliştirme Bölgesi) İçindeki Toplam Firma Sayısı & $16^{*}$ \\
\hline TGB(Teknoloji Geliştirme Bölgesi)' de Devam Eden Proje Sayısı & 16 \\
\hline TGB(Teknoloji Geliştirme Bölgesi) Firmalarının Toplam Proje Bütçeleri & 3.006.493,00 TL \\
\hline TGB(Teknoloji Geliştirme Bölgesi) İçindeki firmalarda çalışan Toplam Ar- Ge Personeli & 33 \\
\hline TGB(Teknoloji Geliştirme Bölgesi)'de yer alan Akademisyen ortaklı firma adedi & 2 \\
\hline TGB(Teknoloji Geliştirme Bölgesi)'yi Dışarıdan Ziyaret Eden Kişi Sayısı & 150 \\
\hline Katılım Sağlanan Ulusal Fuar Sayısı & 5 \\
\hline
\end{tabular}

*Kiralanabilen odalar firmalar tarafından paylaşımlı olarak kullanılabilindiği için, teknoparkta yer alan firma sayısı, kiralanabilen oda sayısından fazla olabiliyor. 


\subsection{Yılında Gerçekleştirilen Faaliyetler}

12 Aralık 2017 Tarihi İtibariyle Alınan Senato Kararı Gereğince; "Sektörel İlişkiler Ve Teknoloji Transfer Ofisi”"nin ismi değiştirilerek yeni bir yapılanma ile "Teknoloji Transfer Ofisi”" kurulmuştur. Kurulan "Teknoloji Transfer Ofisi”, Zafer Teknopark A.Ş ile birlikte çalışmakta ve aşağıdaki faaliyetlerini sürdürmektedir;

1. Tanıtım, farkındalık ve bilgilendirme hizmetleri; bilgilendirme, farkındalık, tanıtım faaliyetlerinin yaygınlaştırılması yoluyla Üniversite-sanayi işbirliğinin oluşturulması, tekno girişimin özendirilmesi ve yaygınlaştırılması, üniversitedeki bilgi ve deneyimin sanayiye doğru aktarılabilmesi, Fikri ve Sınai Mülkiyet Hakları (FSMH) konusundaki bilgi ve bilincin artırılabilmesi hedeflenmektedir. $\mathrm{Bu}$ alanda kazanılan bilgi ve deneyimin paylaşılarak iyi uygulamaların artırılması ve sürdürülebilirliğin sağlanması temel hedef olarak benimsenmektedir. Bu madde kapsamında gerçekleştirilecek faaliyetler tüm diğer maddelerde yer alan konularla ilgili farkındalık, eğitim, tanıtım ve bilgilendirme hizmetlerini kapsamaktadır.

2. Proje Destekleri; araştırma-geliştirme ve inovasyona destek sağlayan programlar, üniversiteler, kamu kurumları ve ticari kuruluşlarda üretilen fikirlerin yayılmasına aracılık yaparak; fikrin araştırmaya ve sonrasında ticari değere dönüşmesine kaynak sağlamaktadır. Bu kapsamda başta üniversite bünyesindeki akademisyenler ve Teknokent'teki firmalar olmak üzere bölgedeki akademisyenleri ve firmaları doğru fon kaynaklarına yönlendirme, ilgili fon kaynakları için proje hazırlama, ortaklık oluşturma, proje yürütme ve raporlama gibi konularda destek ve hizmet sağlanması hedeflenmektedir. Bu hedef doğrultusunda hem akademisyenlerin hem de firmaların ulusal ve uluslararası fon kaynakları hakkındaki farkındalıklarını ve bilgi birikimlerini arttırarak daha fazla bu kaynaklardan yararlanmaları konusunda rehber olunacaktır.

3. Üniversite-Sanayi İşbirliği; Bilgi birikiminin, yeni ürün ve teknolojilerin ortaya çıkmasına sağladığı katkı, günümüzde ekonomik büyümenin temel dayanağını oluşturmaktadır. Ekonomik büyümede bilginin artan önemi ile, bilgiyi üreten akademisyenlere ve araştırma sonucu üretilen bilgi ve teknolojilere erişim sanayi kuruluşları için stratejik bir konu haline gelmiştir. Birim, üniversitenin araştırmacı ve araştırma altyapısını kullanarak hem Teknokent'te yer alan firmalar hem de Organize Sanayi Bölgeleri'nde yer alan firmalar olmak üzere ekosistem dışındaki firmaları kapsayacak şekilde üniversite-sanayi işbirliği ortamının yaratılmasını hedeflemektedir. Birim temelindeki çalışmalar vasıtasıyla üniversite ile buluşturulacak sanayi, ihtiyaçlarını üniversite tarafından sağlanacak hizmetler ile karşılayacaktır. Bu kapsamda gerçekleştirilecek faaliyetler üniversitedeki bilgi ve deneyimin sanayiye aktarılması, Teknokent içi firmalarla üniversite-sanayi işbirliğinin sağlanması, Teknokent dışı firmalarla Üniversite Sanayi İşbirliğinin artırılması ve kümelenme faaliyetlerinin gerçekleştirilmesi temel başlıkları altında özetlenebilir.

4. Fikri ve Sınai Mülkiyet Hakları; Üniversitelerde üretilen bilginin değere dönüşmesi ancak bilginin koruma altına alınması ile sağlanabilmektedir. Fikri Sınai Mülkiyet Hakları (FSMH), koruma altına alınan akademik çalışmaların üretime ve sanayicinin ihtiyacını karşılayacak "ticari değere" dönüş̧ürülmesi; hem ülke ekonomisine katk1 sağlamak hem de üniversitelere finansman kaynakları sağlamak açısından büyük önem taşmaktadır. Bu bağlamda yürütülecek çalışmalarla, buluş sayılarının arttırılması ve özellikle bu buluşların ticarileştirilerek ekonomik değere dönüştürülmesi hedeflenmektedir. Bu sayede, mevcut kurumsal FSMH destek programının geliştirilmesi, FSMH destek programı kapsamında buluşların yönetilmesi, ticarileştirilmesi ve bu konuda farkındalık çalışmalarının arttırılması hedeflenmiştir.

5. Kuluçka merkezi (Girişimcilik); Merkezin hedefi; üniversitedeki bilgi birikiminin hedef kitle olarak görülen öğrenciler ve akademisyenler tarafından kullanılması ve bu bilgi birikiminin ticari bir değere dönüştürülmesini girişimciliği destekleme yolu ile gerçekleştirmektir. Yüksek rekabetçilik ortamında, mevcut pazara hâkim, pazara giriş konusunda gerekli bilgi birikimleri ile donatılmış, finansman ihtiyaçlarını karşılayabilen ve gerekli networklere ulaşabilen girişimciler yetiştirilerek, teknoloji tabanlı şirket sayısını arttırmak hedeflenmektedir. $\mathrm{Bu}$ kapsamda, potansiyel girişimcilerin firma kurmasını kolaylaştırıcı hukuki işlemler, iş geliştirme 
ve pazarlama konularında danışmanlıklar, çekirdek sermayeye ve diğer yatırım imkânlarına ulaşımı kolaylaştırıcı hizmetlerin daha etkin olarak verilmesi, ön kuluçka, kuluçka hizmetleri, iş rehberliği hizmetleri, hızlandırma programları ve girişimcilik akademilerinin temel faaliyetler arasında yer alması sağlanacaktır.

\section{Afyon-Uşak Zafer Teknoloji Geliştirme Bölgesi (Zafer Teknopark A.Ş.) Örneği}

Türkiye'de Afyonkarahisar ve Uşak illerinde bulunan yüksek öğretim kurumları ortaklığında kurulan ilk teknopark özelliği ile aktif teknoparklar arasında yer almaktadır. 2016 yılından itibaren aktif olarak faaliyetlerini sürdüren Zafer Teknopark A.Ş., fiili olarak faaliyetlerine başladığı günden itibaren güçlü bir ivme ile çalışmalarını sürdürmektedir. Aralık 2017 itibariyle teknopark bünyesinde 15 girişimci firma ile \%100 doluluk kapasitesi ile faaliyetlerini sürdürmektedir. Zafer Teknopark A.Ş.'de kuruluşundan itibaren toplam $32 \mathrm{Ar}-\mathrm{Ge}$ projesi bağımsız hakemler tarafından değerlendirmeye tabi tutulmuştur. Kabul edilen projelerden 5 Ar-Ge projesi teknopark bünyesinde başarı ile tamamlanmış, tamamlanan bu projelerin sahibi girişimci firmaların 3'ü yeni proje sunmuşlar ve projeler devam etmektedir. Şirket, girişimci firmalara her iki üniversiteden alanında uzman akademisyenler ile iş birliği imkânı sunarak, sanayici ve akademisyenler arasında köprü işlevini üstlenmiştir.

Çalışmada Afyon Uşak Zafer Teknoloji Geliştirme Bölgesi Yönetici A.Ş. (Zafer Teknopark A.Ş.)' de faaliyet gösteren 15 girişimci firma seçilmiş̧ir. Mevcut girişimciler, yazılım, inşaat, sağlık, geri dönüşüm, elektronik gibi farklı alanlarda faaliyet göstermektedirler.

\subsection{Zafer Teknopark A.Ş. İle Yapılan Nitel Araştırmanın Amacı}

Teknoparklar, piyasanın yetersiz olduğu Ar-Ge ve yenilikçi çabalar için altyapı sağlayarak, vergi ya da genişletilmiş teşvik araçları ile girişimcileri projelerini uygulama noktasında teşvik etmektedirler. Teknoparkların sunduğu bu avantajlar ile; girişimciler toplumun güncel ve gelecekteki ihtiyaçlarına çözümler geliştirebilirler. Çalışmada, özellikle yeni fikir ve buluşları uygulamaya yönelik girişimcilik faaliyetlerinde, teknoparkların katkı ve önemini vurgulamak amaçlanmaktadır. Bu bağlamda Zafer Teknoparkta yer alan girişimcilerin, Teknoparkın sağlamış olduğu imkânlardan yararlanma düzeyleri belirlenmeye çalışılmıştır.

\subsection{Zafer Teknopark A.Ş. İle Yapılan Nitel Araştırmanın Yöntemi}

Gözlem, mülakat ve belge incelemesi gibi veri toplama tekniklerinin kullanıldığı nitel araştırma; algıların ve olayların doğal ortamda gerçekçi ve bütüncül bir kapsamda ortaya konulması yoluyla nitel bir sürecin izlendiği tekniktir (Yıldırım ve Şimşek, 2006, s.39). Nitel araştırma yapılarak elde edilen bulguların sosyal gerçeklikleri açıklayıcı olarak düzenlenmesi mümkün olabilecektir (Altunışık vd., 2012, s.324). Sosyal bilimlerdeki araştırmalarda çalış1lan olay ve olgular kendi ortamlarında incelenmektedir. Çünkü sosyal bilimlerde olay ve olgulara yönelik tek bir "gerçeklik" ya da tek bir "doğru” bulunmamaktadır. Çoklu gerçeklikler; farklı ve çeşitli algılar söz konusu olabilmektedir. Bu alanda, yaşanılan durumlara ilişkin katı kurallar ve genellemeler yapılamaz ancak koşullara göre farklılık gösteren betimlemeler yapılabilir (Yıldırım ve Şimşek, 2016, s.31).

Araştırmada nitel araştırma yöntemlerinden biri olarak kabul edilen betimsel analiz yöntemi uygulanmıştır. Bu yöntemde, elde edilen veriler, önceden belirlenen başlıklar altında özetlenerek yorumlanmaktadır. Veriler, araştırma sorularının ortaya koyduğu başlıklara göre düzenlenebilir ya da görüşme ve gözlem süreçlerinde kullanılan soruların boyutları dikkate alınarak da sunulabilir. Bu analiz türünde, veri kaynaklarından bazı alıntılar yapmak, çalışmanın güvenilirliği yönünden yararlı olabilmektedir. Bu sayede, çarpıcı görüşlerin yansıtılması da mümkün olabilecektir. Bu analizin amacı, elde edilen bulguları düzenlenmiş ve yorumlanmış olarak okuyucuya sunmaktır (Yıldırım ve Şimşek, 2016:239). Girişimcilerin gerçek düşüncelerine ulaşabilmek ve yüksek düzeyli geri dönüşün sağlanması için bu yöntem tercih edilmiştir. 
Çalışmada Zafer Teknopark A.Ş. bünyesinde yer alan girişimcilere yarı yapılandırılmış görüşme yöntemiyle; teknoparkla ilgili bilgiye nasıl ulaştıkları, giriş ile ilgili karşılaştıkları sorunlar, beklentilerinin karşılanma durumu, yeni projelere katkısı var mı gibi sorular sorulmuş ve bu konudaki düşüncelerini ifade etmeleri istenilmiştir. Zafer Teknoparkta bulunan 15 girişimci firmadan 12'sine ulaşılmış ve araştırma bu firmalar üzerinde gerçekleştirilmiştir.

Zafer Teknoparkta yer alan girişimcilerin vermiş oldukları yanıtlara, çalışmanın bulgular bölümünde sıra ile verilmiştir. Taryışma bölümünde ise bulgularda verilen bilgiler yorumlanarak ifade edilmiştir.

\subsection{Zafer Teknopark A.Ş. İle Yapılan Nitel Araştırmanın Kısıtları}

Araştırma sadece Zafer Teknopark A.Ş.'de yer alan girişimcilere uygulanmıştır. Girişimcilerin tamamına ulaşılamamış olunması da araştırmanın kısıtlarındandır. Diğer teknoparklarda yer alan girişimcilere uygulanmamış olması da kısıtlar arasında yer almaktadır. $\mathrm{Bu}$ kısıtlar göz önünde bulundurularak tamamlayıcı çalışmaların yapılması mümkündür.

\subsection{Zafer Teknopark A.Ş. İle Yapılan Nitel Araştırmanın Literatüre Katkısı}

Ülke, bölge ve yerel ekonomilerin çağın gereğini yansıtan yoğun teknoloji ve üretim yöntemleri sayesinde ekonomik anlamda ilerlemeleri beklenmektedir. Ancak bu ilerleme için Teknoparkların sayısının artırılması, mevcut olanların desteklenmesi gerekmektedir. Teknopark kavramının toplum tarafından bilinirliğinin artırılması çabalarına akademik çalışmaların katkısı göz ardı edilemez. Bu anlamda konu ile ilgili yapılan her çalışma konuya farklı bakış açısı getirecek, eksikliklerin görülmesi ve tamamlanmasına vesile olacaktır.

\subsection{Kısıtlar ve Yapılacak Çalışmalara Öneriler}

Çalışmada sadece Zafer Teknopark A.Ş.'de yer alan girişimciler dikkate alınmıştır. Teknopark yönetim ve personelinin görüşlerine yer verilmemiştir. Ayrıca diğer teknoparklarda yer alan girişimcilere, teknopark yönetim ve personeline uygulanmamış olması da kısıtlar arasında yer almaktadır. $\mathrm{Bu}$ kısıtlar göz önünde bulundurularak tamamlayıcı çalışmaların yapılması mümkündür.

\section{Bulgular}

Zafer Teknopark A.Ş. bünyesinde yer alan girişimcilere yarı yapılandırılmış görüşme yöntemiyle konu ile ilgili düşünceleri sorulmuştur. Düşünceleri alınan 12 girişimcinin konu ile ilgili ifadeleri aşağıda özetlenmiştir.

Girişimci 1: Teknoparkta kurulan akademisyen kuruculu, dört aydır faaliyet gösteren ArGe yazılım firması, iki çalışanı var, teknoparkla ilgili bilgiyi üniversite yetkililerinden almış, giriş ile ilgili herhangi bir sorun yaşamamış, teknopark yönetimi tarafından işlerin kolaylaştırıldığını ifade etmekte ve yeni projeler geliştirmeye konusunda teknoparkın katkı sağladığını ifade etmektedir.

Girişimci 2: Teknoparkta kurulmuş, iki yıldır faaliyet gösteren Ar-Ge şahıs şirketi yazılım firması, bir çalışanı var, teknoparkla ilgili bilgiyi eşinden duymuş, giriş ile ilgili herhangi bir sorun yaşamamış, teknopark yönetimi tarafından işlerin kolaylaştırıldığını ifade etmekte ve yeni projeler geliştirme konusunda teknoparkın katkı sağladığını ifade etmektedir.

Girişimci 3: Beş yıldır faaliyet gösteren, ancak son iki yıldır teknoparkta yer alan şahıs şirketi yazılım firması, iki çalışanı var, teknoparkla ilgili bilgiyi sektörden edinmiş, giriş ile ilgili herhangi bir sorun yaşamadığını belirtmiştir. İlk kez teknoparkta yer alan firma, Teknopark yönetiminin kuvvetli iletişim, etkili proje danışmanlık faaliyetleri ile işlerini kolaylaştırdıklarını ve yeni projeler geliştirme konusunda katkı sağladıklarını ifade etmektedir.

Girişimci 4: Yirmi beş yıldır faaliyet gösteren ve teknoparkın kuruluşundan itibaren yer alan limited şirket yazılım firması, on çalışanı var, teknoparkla ilgili bilgiyi sektörden edinmiş, 
giriş ile ilgili herhangi bir sorun yaşamadığını belirtmektedir. İlk kez teknoparkta yer alan firma, Teknopark yönetiminin kuvvetli iletişim, etkili proje danışmanlık faaliyetleri ile işlerini kolaylaştırdıklarını ifade etmektedir. Henüz yeni proje geliştirmemiştir.

Girişimci 5: Teknoparkta kurulmuş, on altı aydır faaliyet gösteren anonim şirket inşaat firması, on çalışanı var, teknoparkla ilgili bilgiyi basından duymuş, giriş ile ilgili herhangi bir sorun yaşamamış, teknopark yönetiminin beklentilerini karşıladığı, işlerinin kolaylaştırıldığını ifade etmekte ve yeni projeler geliştirmeye konusunda teknoparkın katkı sağladığını ifade etmektedir.

Girişimci 6: Sekiz aydır faaliyet gösteren ve dört aydır teknoparkta yer alan limited şirket yazılım firması, iki çalışanı var, teknoparkla ilgili bilgiyi üniversite hocalarından edinmiş, giriş ile ilgili herhangi bir sorun yaşamadığını belirtmektedir. Teknopark yönetiminin beklentilerini fazlasıyla karşıladığını, danışmanlık ve proje destekleri, bilgilendirme hizmetlerinden yararlandıklarını ifade etmektedir. Ayrıca yeni projeler geliştirme konusunda teknoparkın katkı sağladığını belirtmiştir.

Girişimci 7: Yedi yıldır faaliyet gösteren ve yaklaşık bir yıldır teknoparkta yer alan limited şirket yazılım-enerji-makine imalatı firması, yedi çalışanı var, teknoparkla ilgili bilgiyi üniversite toplantılarında edinmiş, giriş ile ilgili herhangi bir sorun yaşamadığını belirtmektedir. İlk kez teknoparkta yer alan firma, sadece vergisel avantajlardan dolayı proje yapmayı tercih ettiğini belirtmiştir. Teknopark yönetiminin henüz beklentilerini tam olarak karşılamadığını, üyeler arasında yeterli iletişim kurulamadığını ifade etmektedir. Henüz yeni proje geliştirmemiştir.

Girişimci 8: Dört yıldır faaliyet gösteren ve yaklaşık bir buçuk yıldır teknoparkta yer alan şahıs şirketi yazılım firması, üç çalışanı var. Teknoparkların çalıştığı sektörle yakın ilişkisi olması nedeniyle teknoparkların kurulmalarını bizzat takip ettiğini ve giriş ile ilgili herhangi bir sorun yaşamadığını belirtmiştir. Zafer Teknopark'tan beklentilerini daha düşük seviyede tuttuğunu belirten girişimci, ilerleyen yıllarda daha başarılı işler yapılacağı kanısını taşımaktadır. Henüz yeni proje geliştirmemiştir.

Girişimci 9: Yaklaşık yedi yıldır faaliyet gösteren ve yaklaşık iki yıldır teknoparkta yer alan limited şirket elektrik-elektronik firması, yirmi otuz arası çalışanı bulunmakta, teknoparkla ilgili bilgiye medyadan ulaşmış, giriş ile ilgili herhangi bir sorun yaşamadığını belirtmektedir. Teknopark yönetiminin beklentilerini karşıladığını ve yeni projeler geliştirme konusunda katkı sağladığını ifade etmiştir.

Girişimci 10: Teknoparkta kurulmuş, yedi aydır faaliyet gösteren şahıs şirketi sağlık firması, bir çalışanı var, teknoparkla ilgili bilgiyi üniversite hocalarından duymuş, giriş ile ilgili herhangi bir sorun yaşamamış. Firma, teknopark yönetiminin beklentilerini karşıladığını, işlerini kolaylaştırarak yönlendirdiklerini, her adımda aktif destek sağladıklarını ve yeni projeler geliştirme konusunda katkı sağladığını belirtmektedir.

Girişimci 11: Teknoparkta kurulmuş, bir yıllık Ar-Ge geri dönüşüm-yalıtım malzemeleri firması, iki yıldır teknoparkta yer almakta, dokuz çalışanı var, teknoparkla ilgili bilgiyi üniversite hocalarından duymuş, giriş ile ilgili herhangi bir sorun yaşamamış. Ayrıca firma, teknopark yönetiminin beklentilerini karşıladığını, işlerini kolaylaştırarak yönlendirdiklerini, proje ve destekler için danışmanlıklarının etkili olduğunu, yeni projeler geliştirme konusunda katkı sağladığını belirtmektedir. Daha önceden duyum almadıkları birçok konuda proje birimi tarafından bilgilendirildiklerini ifade etmektedir.

Girişimci 12: Teknoparkta kurulan bir buçuk yıllık limited şirket yazılım firması, bir çalışanı var, teknoparkla ilgili bilgiyi çalışma hayatında çevresinden edinmiş, giriş ile ilgili herhangi bir sorun yaşamamış. Firma, teknopark yönetiminin beklentilerini fazlasıyla karşıladığını, konu ile ilgili personelin hızlı geri bildirim ve iletişimi işleri kolaylaştırdığını ifade 
etmiştir. Ayrıca firma, teknopark bünyesindeki firmalarla yapılan fikir alış verişlerinin mevcut ve yeni projeler geliştirme konusunda katkı sağladığını belirtmektedir.

\section{Tartışma}

Görüşleri alınan 12 girişimcinin tamamının erkek olduğu görülmektedir. Tablo5'e bakıldığında genç girişimcilerin çoğunlukta olduğu anlaşılmaktadır. Teknoparkta yer alan girişimcilerin faaliyet süreleri 4 aydan 25 yıla uzanan bir çeşitlilik göstermektedir. Ayrıca girişimlerden 6's1 yani yarısı teknoparkta kurulmuştur.

Tablo 5. Girişimcilerin yaş aralığ

\begin{tabular}{lll}
\hline Yaş Aralı̆̆ı & $21-40$ & $41-60$ \\
\hline Girişimci Sayısı & 7 & 5 \\
\hline
\end{tabular}

Tablo 6. Girişimci firmalarda çalışan sayısı

\begin{tabular}{llllllll}
\hline $\begin{array}{l}\text { Çalışan } \\
\text { Sayısı }\end{array}$ & 1 & 2 & 3 & 7 & 9 & 10 & $20-30$ \\
\hline $\begin{array}{l}\text { Girişimci } \\
\text { Sayısı }\end{array}$ & 3 & 3 & 1 & 1 & 1 & 2 & 1 \\
\hline
\end{tabular}

Tablo 6' ya bakıldığında girişimci firmalarda çalışan sayısının az olduğu görülmektedir. Altı girişimde çalışan sayısı 1-2 kişi iken, en az 10 kişi çalışan 3 firma bulunmaktadır. Çalışan sayısı açısından teknoparktaki firmalar genel olarak küçük firma niteliğindedir. Girişimcilerin tamamı teknoparka girişle ilgili bir engel ya da sorunla karşılaşmadıklarını ifade etmişlerdir. Girişimciler büyük bir çoğunlukla beklentilerinin karşılandığını, yetkililerin kendilerini bilgilendirdiklerini ve üyeler arası iletişimin giderek güçlendiğini belirtmişlerdir. Girişimci firmalar, gerek teknopark yönetimi, gerekse üyeler arası iletişim ve bilgi alışverişi sayesinde yeni fikirler ve projeler geliştirdiklerini vurgulamışlardır. Gözlemlerimiz sonucu; en son teknopark ailesine katılan girişimci firmanın beklentilerinin fazlasıyla karşılandı̆̆ katılan girişimci firmaların ise beklentilerini düşük tuttukları anlaşılmaktadır. Elde edilen bu bulgular, her geçen gün teknopark yönetim ve çalışanlarının konularında uzmanlaştıklarını; girişimci firmalara etkili ve verimli hizmet sunduklarını belirtmektedir. Çalışmada, girişimcilerin teknoparkın sağlamış olduğu imkânlardan yararlanma düzeyleri belirlenmesi amaçlanmaktadır. Dolayısıyla belirtilen bulgular sayesinde, teknoparkın kuruluş amacını gerçekleştirmekte olduğu ifade edilebilir. Ve yine, Zafer Teknopark'1n giderek artan derecede sürdürülebilir başarı sağladığının belirtilmesi de mümkündür.

\section{Sonuç ve Öneriler}

Günümüz koşullarında bir ülkenin refah düzeyinin artması ve ekonomik kalkınmayı sağlaması, teknoloji yoğun ürün ve üretim yöntemleri geliştirebilme yeteneği ile mümkün olabilecektir. Bu durumun gerçekleşebilmesi için ülkelerin, mucit girişimcileri destekleyen bir ekosistem oluşmasını sağlamaları gerekmektedir. Söz konusu ekosistemi içerisinde barındıran yap1 ise "teknopark" ya da "teknoloji geliştirme bölgeleri" dir. Teknoparklar üniversite- sanayi işbirliği içerisinde çift yönlü faydayı mümkün kılmaktadır. Üniversiteler girişimci firmalara; ArGe çalışmaları için uygun mekân, danışmanlık hizmetleri ve diğer girişimci firmalar arasında sinerji yaratılarak yeni ürün ve projelerin gelişmesi için desteği teknoparklar vasıtasıyla sunarlar. Üniversitelerin sanayi ile işbirlikleri sonucu, mezunlarına ve öğrencilerine istihdam sağlamaları, ayrıca hem öğrencilerine hem de öğretim elemanlarına Ar-Ge faaliyetlerini gerçekleştirebilecekleri bir ortam yaratmaları teknoparklar sayesinde mümkün olmaktadır. Başka bir ifadeyle; "bu yapı aslında girişimcilik ekosisteminin oluşmasını mümkün kılmaktadır" denilebilir. Ayrıca devletin teknoparklara sağlamış olduğu teşvik ve vergi avantajı ile; üniversitesanayi-devlet üçlü bir güç birliği sağlamaktadır.

Dünyada yaklaşık 1950'li yıllarda başlayan teknopark uygulamaları, Türkiye'de 2001 yılında yasal alt yapının oluşturulmasıyla gecikmeli olarak yaşama geçirilmiştir. Afyon-Uşak Zafer Teknoloji Geliştirme Bölgesi (Zafer Teknopark A.Ş.) de 2016 yılında faaliyete geçmiş ve oldukça kısa bir sürede Teknoparktaki tüm ofislerini girişimci firmalara kiralayarak, projelerini uygulamaları için onlara uygun ortam temin etmiş ve etmektedir. Yapılan çalışma ile teknoparkta 
ilk yer alan girişimci firmaların imkânlara erişimi ile daha sonra yer alanların erişiminin daha tatmin edici olduğu kanısına varılmıştır. Yeni kurulan bir teknopark olmasına rağmen görüşleri alınan girişimci firmaların büyük çoğunluğunun beklentilerinin karşılandığı, yeni projeler oluşturdukları, teknik altyapı ve danışmanlık faaliyetlerinin her geçen gün artarak güçlendiği fikri oluşmuştur. Dolayısıyla teknoparklar yeni iş fikirlerinin hayata geçirilmesinde sağladıkları destek ve teşviklerle girişimciliği hızlandırmaktadırlar. Ayrıca teknoparklarda yer alan girişimci firmaların en az yarısının, yeni proje vermeleri ile; teknoparkların proje kültürünün gelişimine katkı sağladığını ifade etmek de mümkündür.

Teknoparkta yer alan girişimci firmaların büyük çoğunluğunun 21-40 yaş arasında olmaları genç girişimcilerin desteklendiğini göstermektedir. Ancak teknoparkta yer alan girişimcilerin tamamı erkektir. Bu da kadın girişimcilere ulaşabilmek ve onları da teknopark bünyesine dahil edebilme çabası gerektiğini göstermektedir. Teknoparkta yer alan girişimcilerin az sayıda personel istihdam ettikleri görülmektedir. Ayrıca teknoparkta yer alan girişimci firmaların yaklaşık yarısı teknopark bünyesinde faaliyete geçen firmalardır. Teknopark bünyesinde projelerini başarı ile tamamlayan girişimcilerin yeni projeler geliştirdiği görülmektedir. Bu durum hem teknoparkların sağladığı imkân ve desteklerle girişimciliğin teşvik edildiğini hem de proje kültürünü geliştirmek için teknoparkların uygun ortamlar oluşturduğunu göstermektedir. Burada teknopark yönetim ve ekibinin, teknoparkta yer alan diğer girişimci firmaların ve onlarla yapılan fikir alışverişlerinin etkili olduğu girişimci firmalar tarafından bildirilmiştir. Teknopark farklı ya da aynı sektörden girişimcilerin bir araya gelerek etkileşimde bulunmalarına da firsat tanımaktadır. Firmalar teknoparkların hem bilgilendirici uzman personeli vasıtasıyla hem de diğer girişimcilerle kurmuş oldukları iletişim bağlantıları ile daha hızlı yol aldıklarını dile getirmişlerdir.

Dünyadan yaklaşık elli yıl sonra Türkiye'de kurulmaya başlayan Teknoparkların aradaki mesafeyi hızla kapatması gerekmektedir. Çalışmada, girişimcilerin teknoparkın sağlamış olduğu imkânlardan yararlanma düzeyleri belirlenmesi amaçlanmıştır. Yapılan çalışmanın sonucu olarak; Afyon-Uşak Zafer Teknoloji Geliştirme Bölgesi (Zafer Teknopark A.Ş.)'nin kuruluşundan günümüze göstermiş olduğu faaliyetlerin umut verici olduğunu ifade etmek gerekmektedir. Teknopark kapsamında yer alan girişimcilerin, girişimcilik sürecinin hemen hemen her aşamasında teknopark tarafindandan sağlanan bilgi ve her türlü destek anlamında yararlanabildikleri anlaşılmaktadır. Ayrıca Zafer Teknopark A.Ş. Türkiye'de ilk olarak, iki farklı ilde yer alan üniversitelerin işbirliğinde kurulmuştur. Dolayısıyla diğer teknoparklardan farklı olarak yaratacağı faydanın da iki kat ve hatta kat kat fazla olması düşüncesini yaratmaktadır. Zafer Teknoparkın girişimcilik sürecinde girişimcilik faaliyetlerini destekleyerek, hem girişimciliğin özendirlmesi ve geliştirilmesine katkı sağladığı, hem de bulunduğu bölge ve dolayısıyla da ülke gelişiminde önemli bir unsur olduğunun ifade edilmesi mümkündür.

\section{Kaynakça}

Altunışık, R., Coşkun, R., Bayraktaroğlu, S., Yıldırım, E. (2012). Araştırma Yöntemleri, Geliştirilmiş 7.Bask1, İstanbul: Sakarya Yayıncılık.

Alkibay, S., E.Orhaner, S. Korkmaz ve A.Ermeç vd. (2012). Üniversite Sanayi İşbirliği Çerçevesinde Teknoparklar, Yönetimsel Sorunları ve Çözüm Önerileri, Atatürk Üniversitesi İktisadi ve İdari Bilimler Dergisi, 26(2):65-90.

Başalp, A. ve Yazlık B. (2006). Türkiye'de Teknoparklar ve Sorunları, inet-tr'06-XI. “Türkiye'de İnternet” Konferansı Bildirileri 21-23 Aralık 2006, TOBB Ekonomi ve Teknoloji Üniversitesi, Ankara: 275-278.

Bilim Sanayi ve Teknoloji Bakanlığı, Bilim ve Teknoloji Genel Müdürlüğü, "Teknoloji GeliştirmeBölgeleri",https://btgm.sanayi.gov.tr/Handlers/DokumanGetHandler.ashx?dokum anId=79697c38-21c9-4206-8104-0d95bd342fc9, (Erişim tarihi: 30.05.2018). 
Bülbül, Y. ve Özbay R.D (2011). Teknoparklar Teknolojik Bilginin Ticarileşmesi, İstanbul Ticaret Odası Yayınları, 2010-111, İstanbul.

Cansız, M. (2017). 2023’e Doğru Türkiye Teknoparklarl, T.C. Kalkınma Bakanlığı Yayın No:2972, Sosyal Sektörler ve Koordinasyon Genel Müdürlüğü.

Cansız, M., Ulusoy, D. (2017a), Teknoloji Tabanlı Girişimcilerin Başarısında Yapısal, Ekonomik, Sosyal, Kültürel ve Beşeri Sermayenin Etkileri: Türkiye Örneği, Sosyoloji Konferansları, (56) :113-149

Ergen, M. (2014). Girişimci Kapital Silikon Vadisi Tarihi ve Startup Ekonomisi, İstanbul, Koç Üniversitesi Yayınlar1.

Gülbaş, S.Y. (2011). İnovasyon: Teknopark Modeli, ANKEM Dergi, 2011;25 (Ek 2): 139-145.

Halıcı, E. (2008). Girişimcilik ve Teknoparklar: Girişimciliğin Eski ve Yeni Yüzü, http://www.emo.org.tr/ekler/1f860e3b7f548ab_ek.pdf, (Erişim tarihi:21.05.2018).

Harmanc1, M. ve Önen, M.O. (1999). Dünyada ve Türkiye'de Teknopark ve Teknokent Uygulamaları, GA/99-2-4, Ankara:Türkiye Kalkınma Bankası A.Ş. Araştırma Müdürlüğü.

İpek, H.B. (2015). İnovasyon Temelli Ekonomi Yapısında Ulusal İnovasyon Sistemi ve Bölgesel İnovasyon Stratejileri, Yayınlanmamış Yüksek Lisans Tezi, Afyon Kocatepe Üniversitesi, Afyonkarahisar.

Marangoz, M. (2016). Girişimcilikte Güncel Konular ve Uygulamalar, İstanbul: Beta Yayınları.

Özkaşıç̧ı, I. (2013). Dijital Çă̆’da Girişimcilik Ekosistemi, İstanbul: Butik Yayınc1lık.

Teknoloji Geliştirme Bölgeleri Uygulama Yönetmeliği. (2014). Resmi Gazete, 12.03.2014.

Tepe, S ve Zaim, H. (2016). Türkiye'de ve Dünyada Teknopark Uygulamaları: Teknopark İstanbul Örneği, İstanbul Ticaret Üniversitesi Sosyal Bilimler Dergisi, (29): 19-43.

Yalçıntaş, M. (2014). Üniversite-Sanayi-Devlet İşbirliğinin Ülke Ekonomilerine Etkileri: Teknopark İstanbul Örneği, Finansal Araştırmalar ve Çalışmalar Dergisi, 5(10): 83-106.

Yıldırım A., Şimşek H. (2006). Sosyal Bilimlerde Nitel Araştırma Yöntemleri, 5. Baskı, Ankara: Seçkin Yayınları.

Yıldırım, A. ve Şimşek, H. (2016). Sosyal Bilimlerde Nitel Araştırma Yöntemleri, Genişletilmiş 10. Bask1, Ankara: Seçkin Yayınları. 